\section{ANNOUNCEMENTS OF THE EFORT}

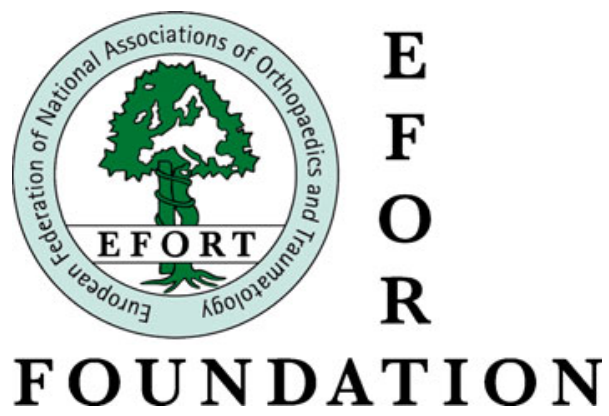

The EFORT FOUNDATION visiting fellowship programme

The EFORT FOUNDATION was launched in 2009. Its aim is to support knowledge exchange and training in orthopaedics and traumatology. As one of its first projects, in 2010 the FOUNDATION began to support visiting fellowships. With the donations from Zimmer $\mathrm{GmbH}$ and the Zurich Insurance Company, 50 visiting fellowships were organised that first year. They were very well received. We would like to share some of the comments we got back from the fellows:

- "...I think I have made the absolute most of the opportunity that was given to me, as I've been able to learn new surgical methods..."

- “...a unique experience..."

- “...a great opportunity to get to know more developed Western European countries and, in this way, try to improve our own management of orthopaedic patients..."

- "...I had the chance to see and participate in all kinds of surgery..."

- “...I was able to upgrade my personal knowledge, gain experience in new techniques and learn about up-todate methods for diagnostics and the treatment of different kinds of pathologies..."

- "...This visiting fellowship was a great experience for me, and I will recommend it to the other orthopaedic surgeons I know..."

- "...I integrated easily into the life and activities of the clinic..."

- “...The professional achievement was remarkable, but the rich social and cultural aspects of this programme made it a truly bright, unforgettable and an exciting experience which enriched me as a human being..."
Do not miss the opportunity to apply for an EFORT FOUNDATION visiting fellowship: www.efortfoundation.org
- “...we were able to compare the operating techniques of both orthopaedic departments..."

- "...to see different treatment methods, other practices and different public health systems..."

- "...to share an experience of work between our countries, have interesting and helpful discussions and find out new ways of applying treatment technologies..."

- “...improved my medical knowledge and gave me an insight to other European medical systems..."

- "...extremely useful for my future career..."

- "...I truly hope that there will be more opportunities for further training support..."

In view of the programme's success in 2010, the EFORT FOUNDATION will continue to support short- and longterm fellowships for surgeons in orthopaedics and traumatology. Active surgeons from Europe, the Middle East and Africa will be offered the opportunity to expand their knowledge, learn new techniques, undertake research and meet other colleagues and cultures.

Several clinics have agreed to host visiting fellows in their departments. Each applicant can choose his/her preferred hospital in which to complete his/her fellowship. At the moment, we have 84 great teaching hospitals in 18 European countries on board. Each host department prepares an interesting and individual programme for their fellows to make their stay successful and memorable.

More information about the EFORT FOUNDATION, its visiting fellowship programmes and current projects is available at www.efortfoundation.org.

Prof. Dr. Karl-Göran Thorngren, Chairman EFORT FOUNDATION Prof. Dr. Philippe Neyret, Chairman EFORT Fellowships 